\section{Anaphylaxie bei Impfung: viele Auslöser?}

\author{
Allergische Reaktionen auf Influenzavakzinen sind selten. Meist liegt \\ eine Überempfindlichkeit gegen Hühnerei oder Gelatine zugrunde. \\ Doch auch Reaktionen auf das infektiöse Agens selbst kommen vor.
}

T exanische Allergologen berichten über einen 37-Jährigen Mann, der 15 Minuten nach einer Grippeschutzimpfung u.a. über ein generalisiertes Wärmegefühl, Gesichtsrötung, Pruritus und Gefühllosigkeit der Lippen klagte. An der Injektionsstelle am rechten Oberarm zeigte sich eine lokalisierte Reaktion, Atembeschwerden bestanden nicht. Der Patient erhielt zunächst $10 \mathrm{mg}$ Cetirizin und wegen dann rasch zunehmender Symptome Adrenalin i. m. und Ranitidin oral. Die Beschwerden verschwanden nach 30 Minuten wieder.
Die Anamnese ergab, dass der Mann bereits vier Jahre zuvor eine Lokalreaktion nach einer Influenzaimpfung beobachtet hatte. Andere Impfungen waren dagegen ohne Probleme verlaufen, eine Nahrungsmittelallergie gegen Eier oder Gelatine wurde verneint. Im Hauttest zeigte sich eine positive Reaktion auf die Influenzavakzine und auf Gelatine. Im IgE-Immunoblot mit Patientenserum wurde eine Proteinbande bei $100 \mathrm{kDa}$ detektiert, was dem Molekulargewicht des Gelatineproteins entspricht, außerdem eine Bande bei $68 \mathrm{kDa}$, entsprechend dem Molekulargewicht des Häm-
agglutinin-Proteins aus dem Impfstoff, sowie eine $45-\mathrm{kDa}-\mathrm{Bande}$, entsprechend dem Molekulargewicht von Ovalbumin des Kükenembryos bzw. des Eies. Mit Kontrollseren traten die Banden nicht auf. Dem Patient wurde empfohlen, sich in Zukunft nicht mehr routinemäßig gegen Grippe impfen zu lassen.

Fazit: Als mögliche Ursachen für eine allergische Sofortreaktionen nach einer Grippeschutzimpfung konnten nicht nur Sensibilisierungen gegen Hühnerei und Gelatine, sondern auch eine Sensibilisierung gegen das infektiöse Agens selbst gefunden werden. Im vorliegenden Fall handelte es sich um Hämagglutinin, wie es von allen drei Virusstämmen in der Vakzine produziert wurde. $\quad b k$

Coop CA et al. Anaphylaxis from the influenza virus vaccine. Int Arch Allergy Immunol 2008; $146: 85-8$

\title{
Anaphylaxiegefahr bei Nüssen abschätzen
}

\section{Baumnuss- und Erdnussallergien werden immer häufiger. Bei wem das Risiko für eine lebensbedrohliche Anaphylaxie durch diese Nah- rungsmittel besonders hoch ist, untersuchte eine britische Studie.}

\begin{abstract}
$\stackrel{\bullet}{\wedge}$ rzte der Universität Manchester dokumentierten über zwölf Jahre hinweg die Symptome und Allergietestergebnissen von 1.094 Patienten mit Erdnuss- oder Baumnussallergie. Außerdem analysierten sie bei einem Teil der Patienten $(\mathrm{n}=122)$ auch das Serum auf Enzyme des Bradykinin-Metabolismus, da Bradykinin ein wichtiger Mediator anaphylaktischer Reaktionen ist. Von den Probanden waren $76 \%$ jünger als 16 Jahre. Die große Mehrheit der Patienten reagierte am deutlichsten auf Erdnuss (80\%), je 7\% auf Cashew- oder Paranüsse, 3\% auf Walnüsse, 2\% auf Haselnüsse und je $1 \%$ auf Mandeln bzw. Pinienkerne. Bei Nussexposition entwickelten $37 \%$ der Patienten lediglich Urtikaria und Angioödeme, die übrigen auch pharyngeale Ödeme, Bronchospasmus oder Bewusstseinstrübung.

Erwachsene zeigten im Vergleich zu Kindern eher schwere Pharynxödeme,
\end{abstract}

Bronchospasmus und insbesondere Bewusstseinsverlust (Odds Ratio [OR] jeweils 3,7, 2,0, 8,9). Ausgeprägte Rachenödeme waren besonders häufig bei Patienten mit einer schweren allergischen

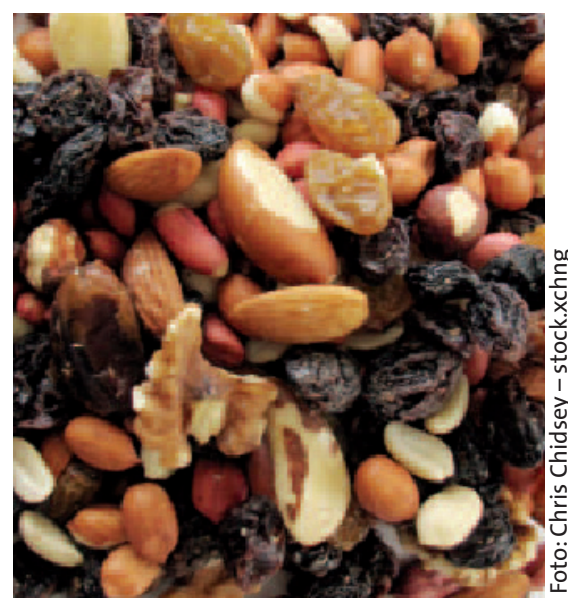

Nussallergie - das klinische Bild ist unterschiedlich
Rhinitis (OR 3,8) und außerdem bei Allergien gegen Baumnüsse wahrscheinlicher als bei Allergien gegen Erdnüsse (OR 2,6). Patienten mit einem Asthma bronchiale waren besonders häufig von schweren, lebensbedrohlichen Reaktionen der unteren Atemwege betroffen (OR 6,8), Studienteilnehmer mit einer atopischen Dermatitis besonders häufig von systemischen Kreislaufreaktionen mit Bewusstlosigkeit (OR 3,1).

Die Laborparameter wiesen auf einen Zusammenhang zwischen niedrigen Konzentrationen des Angiotensin-konvertierenden Enzyms (ACE) und einem erhöhten Risiko für schwere Pharynxödeme hin (OR 9,6 bei ACE-Serumkonzentration $<37,0 \mathrm{mmol} / \mathrm{l})$. ACE ist maßgeblich am Abbau von Bradykinin beteiligt.

Fazit: Alter, atopische Erkrankungen und Bardykinin-Metabolismus scheinen für die Ausprägung des klinischen Bildes bei Baum- oder Erdnussallergie relevant zu sein.

\section{$f k$}

Summers $\mathrm{CW}$ et al. Factors predicting anaphylaxis to peanuts and tree nuts in patients referred to a specialist center. J Allergy Clin Immunol 2008; 121: 632-638 